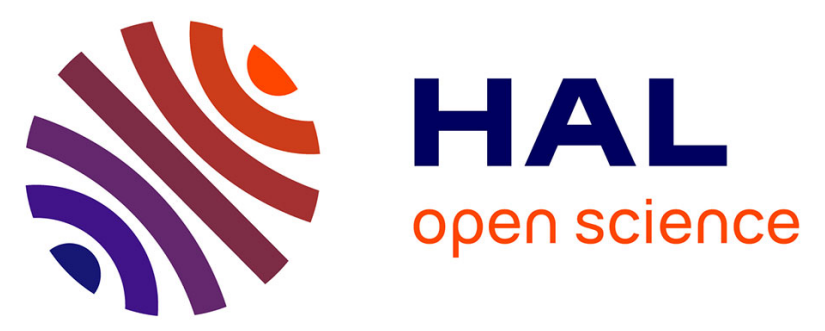

\title{
Synergistic effect of cellulose nanocrystals/graphene oxide nanosheets as functional hybrid nanofiller for enhancing properties of PVA nanocomposites
}

Nassima El Miri, Mounir El Achaby, Aziz Fihri, Mohamed Larzek, Mohamed Zahouily, Karima Abdelouahdi, Abdellatif Barakat, Abderrahim Solhy

\section{To cite this version:}

Nassima El Miri, Mounir El Achaby, Aziz Fihri, Mohamed Larzek, Mohamed Zahouily, et al.. Synergistic effect of cellulose nanocrystals/graphene oxide nanosheets as functional hybrid nanofiller for enhancing properties of PVA nanocomposites. Carbohydrate Polymers, 2016, 137, pp.239-248. 10.1016/j.carbpol.2015.10.072 . hal-01269355

\section{HAL Id: hal-01269355 https://hal.science/hal-01269355}

Submitted on 27 May 2020

HAL is a multi-disciplinary open access archive for the deposit and dissemination of scientific research documents, whether they are published or not. The documents may come from teaching and research institutions in France or abroad, or from public or private research centers.
L'archive ouverte pluridisciplinaire HAL, est destinée au dépôt et à la diffusion de documents scientifiques de niveau recherche, publiés ou non, émanant des établissements d'enseignement et de recherche français ou étrangers, des laboratoires publics ou privés. 


\section{Accepted Manuscript}

Title: Synergistic effect of cellulose nanocrystals/graphene oxide nanosheets as functional hybrid nanofiller for enhancing properties of PVA nanocomposites

Author: Nassima El miri Mounir El achaby Aziz Fihri Mohamed Larzek Mohamed Zahouily Karima Abdelouahdi

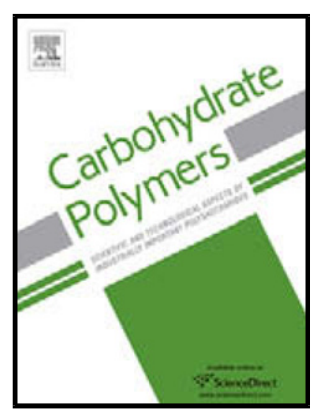
Abdellatif Barakat Abderrahim Solhy

PII: S0144-8617(15)01052-8

DOI: http://dx.doi.org/doi:10.1016/j.carbpol.2015.10.072

Reference: CARP 10489

To appear in:

Received date: $\quad$ 11-6-2015

Revised date: 2-10-2015

Accepted date: $\quad 22-10-2015$

Please cite this article as: El miri, N., El achaby, M., Fihri, A., Larzek, M., Zahouily, M., Abdelouahdi, K., Barakat, A., and Solhy, A.,Synergistic effect of cellulose nanocrystals/graphene oxide nanosheets as functional hybrid nanofiller for enhancing properties of PVA nanocomposites, Carbohydrate Polymers (2015), http://dx.doi.org/10.1016/j.carbpol.2015.10.072

This is a PDF file of an unedited manuscript that has been accepted for publication. As a service to our customers we are providing this early version of the manuscript. The manuscript will undergo copyediting, typesetting, and review of the resulting proof before it is published in its final form. Please note that during the production process errors may be discovered which could affect the content, and all legal disclaimers that apply to the journal pertain. 


\section{Synergistic effect of cellulose nanocrystals/graphene oxide} nanosheets as functional hybrid nanofiller for enhancing properties of PVA nanocomposites

Nassima El miri ${ }^{\mathrm{a}, \mathrm{b}}$, Mounir El achaby ${ }^{\mathrm{c},}{ }^{*}$, Aziz Fihri $^{\mathrm{b}}$, Mohamed Larzek ${ }^{\mathrm{c}}$, Mohamed Zahouily ${ }^{\mathrm{a}}$, Karima Abdelouahdi ${ }^{\mathrm{d}}$, Abdellatif Barakat ${ }^{\mathrm{e}}$, Abderrahim (1) Solhy ${ }^{\mathrm{c}, *}$

${ }^{a}$ Faculté des Sciences et Techniques, Université Hassan II-Casablanca, Casablanca 20650, Morocco.

${ }^{\mathrm{b}}$ MAScIR Foundation-INANOTECH, Rabat Design, Rue Mohamed El Jazouli, Madinat Al Irfane 10100 Rabat, Morocco.

${ }^{\mathrm{c}}$ Center for Advanced Materials (CAM), Université Mohammed VI Polytechnique (UM6P), Lot 660-Hay Moulay Rachid, 43150 Ben Guerir, Morocco.

${ }^{\mathrm{d}}$ Faculté des Sciences et Techniques, University Cadi Ayyad, Avanue A. Khattabi, BP 549, 40000 Marrakech. Morocco

${ }^{\mathrm{e}}$ INRA, UMR 1208 Ingénierie des Agropolymères et Technologies Emergentes (IATE) 2, place Pierre Viala - 34060 Montpellier Cedex 1, France.

*Corresponding authors. Tel.: (+2126) 62010 620; E-mail addresses:

mounir.elachaby@um6p.ma (M. El achaby); abderrahim.solhy@um6p.ma (A. Solhy); 


\section{Abstract}

Novel functional hybrid nanofillers composed of cellulose nanocrystals (CNC) and graphene oxide nanosheets (GON), at different weight ratios $(2: 1 ; 1: 1$ and $1: 2)$, were successfully prepared and characterized, and their synergistic effect in enhancing the properties of poly (vinyl alcohol) (PVA) nanocomposites was investigated. Due to the synergistic reinforcement, it was found that the Young's modulus, tensile strength and toughness of the PVA nanocomposite containing $5 \mathrm{wt} \%$ hybrid nanofiller $(1: 2)$ were significantly improved by $320 \%, 124 \%$ and $159 \%$, respectively; and the elongation at break basically remained compared to the neat PVA matrix. In addition, the glass and melting temperatures as well as the moisture sorption of nanocomposites were also enhanced. This synergistic effect improved the dispersion homogeneity by avoiding the agglomeration phenomenon of nanofillers within the polymer matrix, resulting in nanocomposites with largely enhanced properties compared to those prepared from single nanofiller (CNC or GON). The preparation of these hybrid nanofillers and their incorporation into a polymer provided a novel method for the development of novel multifunctional nanocomposites based on the combination of existing nanomaterials.

\section{Keywords}

Cellulose nanocrystals; graphene oxide; hybrid nanofiller; nanocomposite; synergistic reinforcement; mechanical properties. 


\section{Introduction}

In the past two decades, polymer nanocomposite materials have drawn tremendous interest from both scientists and engineers due to their improved properties caused by the inclusion of nanoscale fillers. Novel functional nanocomposites have been constantly emerging in industry applications (Hu, Kulkarni, Choi, \& Tsukruk, 2014; Njuguna, Silva, \& Sachse, 2011). The polymer nanocomposites consist of a polymeric matrix and a dispersed filler, where at least one dimension is <100 nm (Rodríguez-González et al., 2012). The nanometric scale and the type of nanofiller provide an important effect to the polymer matrix, improving the resulting properties of nanocomposites in comparison with those of an individual component (Chivrac, Pollet, \& Avérous, 2009; Paul \& Robeson, 2008). It was reported that the reinforcement in polymer nanocomposites depends strongly on the dispersion of nanofillers in the polymer matrix and the interfacial interaction between nanofillers and the polymer matrix (Jose \& Thomas, 2014a). Recently, hybrid reinforcements of polymer nanocomposites are gaining increased acceptance. In this context, the combination of two kinds of nanofillers in one functional hybrid nanofiller has attracted great interest (Dhibar, Bhattacharya, Ghosh, Hatui, \& Das, 2014; George et al., 2014; Jose \& Thomas, 2014a; Tang et al., 2009). Indeed, hybrid nanofillers can be designed to achieve a synergistic effect and endow a hot matrix with better performance (Wang et al., 2014a).

Recent studies on nanocomposites based on hybrid nanofillers have been focused mainly on thermoplastics and thermosets (Chatterjee et al., 2012; Jose \& Thomas, 2014a, b; Wang et al., 2014a; Yuan et al., 2014). In these nanocomposite systems, the synergistic effect of two kinds of nanofillers was the key factor in improving the physico-chemical properties. Depending on the shape, size and surface characteristics of each nanofiller type and the way they are combined, a change in the morphology and microstructure is expected (Jose \& Thomas, 2014a, b; Tang, Hackenberg, Fu, Ajayan, \& Ardebili, 2012). In most cases, a 3-D 
interconnected microstructural network can be formed when two kinds of nanofillers are combined in one hybrid nanofiller, which drastically affect the properties of the resulting nanocomposites (Jose \& Thomas, 2014a, b). Currently, various hybrid nanofillers have been used as reinforcements for high performance nanocomposites. Table 1 summarizes some hybrid nanofillers that were recently used in nanocomposites development. In most cases, the use of such hybrid nanofillers as a reinforcing phase was achieved in order to enhance the properties of nanocomposites, to introduce some novel properties, or to solve some problems lie to the agglomeration phenomenon and/or interfacial adhesion.

In the current investigation, we demonstrate that the combination of 1-D needle like cellulose nanocrystals (CNC) and 2-D flake-like graphene oxide nanosheets (GON) can engender the formation of 3-D hybrid nanofiller, which is suitable for polymer nanocomposite development. The GON (up to $5 \mu \mathrm{m}$ in lateral size and about $0.8-1.2 \mathrm{~nm}$ in thickness) are essentially graphene nanosheets on which oxygen-containing functional groups are thought to be present in the form of carboxyl, hydroxyl and epoxy groups (El Achaby et al., 2012a, b; Rodríguez-González et al., 2012; Szabo et al., 2006). Currently, GON have been widely used as a single nanofiller for enhancing the properties of water-soluble polymer (El Achaby, 2012a; El Achaby et al., 2014; Layek et al., 2013; Rodríguez-González et al., 2012; Xu, Hong, Bai, Li, \& Shi, 2009). In this context, it was reported that the incorporation of low GON content $(<3 \mathrm{wt} \%)$ into a polymer matrix enhanced the properties of resulting nanocomposite materials. Unfortunately, at high loading level (>3 wt $\%)$ the agglomeration tendency can limit its reinforcing efficiency (Jose, Al-Harthi, Al Maadeed, \& Dakua, 2015; Xu et al., 2009; Zhang, Zhang, \& Madbouly, 2015). Alternatively, the combination of GON with other nanomaterial can bridge adjacent nanosheets and inhibit their aggregation, which enables the material to achieve its highest potential for improving the performance of nanocomposites (Li, Yang, Yu, Zheng, \& Liao, 2011; Zhang, Huang, Tjiu, Fan, \& Liu, 2012). 
Due to its large surface area, high modulus, low density, biocompatibility and biodegradability behaviors, $\mathrm{CNC}$ have been widely used as nanofillers to enhance the properties of nanocomposites (El Miri et al., 2015a, b). The CNC can have a rod-, ribbon- or needle-like shapes, with a length ranging from $100 \mathrm{~nm}$ to $1-2 \mu \mathrm{m}$, and a diameter of about 5$20 \mathrm{~nm}$ (El Miri et al., 2015a, b). Additionally, CNC with high crystallinity and controlled morphology can be extracted from renewable biosourced materials, such as sugarcane bagasse, the by-product used in this work for CNC extraction (El Miri et al., 2015a).

Due to the hydrophilic nature of CNC and GON, their combination can be resulted in the formation of a new hybrid nanofiller. It is worth noting that the abundant oxygen containing groups decorated in GON would interact with the hydroxyl groups and oxygen atoms in CNC, which is beneficial to homogeneously disperse the $\mathrm{CNC}$ and the GON in the formed hybrid nanofiller. Relatedly, CNC and GON have recently been combined to form new structures, such as hybrid composite films (Chen et al., 2014; Sadasivuni et al., 2015; Valentini, Cardinali, Fortunati, Torre, \& Kenny, 2013).

The main objective of this study is to broaden the application of existing nanomaterials (CNC and GON) via their combination into a novel hybrid nanofiller for nanocomposites development. This was accomplished by taking into account the socalled synergistic effect of 1-D elongated CNC and 2-D exfoliated GON, which leads in the formation of a network microstructure. This synergistic effect improved the dispersion homogeneity by avoiding the agglomeration phenomenon of nanofiller within the polymer matrix, resulting in nanocomposite materials with largely enhanced properties compared to those prepared from single component nanofiller (like CNC or GON). Herein, the mixing of CNC and GON occurred in water and the obtained hybrid nanofiller (coded as C:G hybrid nanofiller) was characterized and successfully used as a novel functional hybrid nanofiller to produce high performance PVA nanocomposite films via the 
solvent casting method. For this purpose, the weight loading level of C:G hybrid nanofiller was fixed at $5 \mathrm{wt} \%$, and the obtained results were compared with those found by adding 5 wt $\%$ of either CNC or GON. Additionally, in order to understand the synergistic effect generated from the combination of both kinds of nanomaterials, three C:G hybrid nanofillers have been prepared by varying their weight ratio (i.e C:G-2:1, C:G-1:1 and C:G-1:2). The preparation of these hybrid nanofillers and their incorporation into the polymer matrix provide a promising route for developing innovative materials, mainly by improving the mechanical properties of nanocomposite films in applications where good strength and flexibility are required, such as in food packaging applications.

\section{Materials and experimental detail}

\subsection{Materials}

The sugarcane bagasse (SCB) was provided by a SUNABEL-COSUMAR Group, a company located in the region of Gharb-Loukkos, Morocco. Firstly, the SCB was ground using a precision grinder (Fritsch-Pulverisette 19, GmbH) equipped with a $1 \mathrm{~mm}$ sieve. Then, this fraction was sifted in a $150 \mathrm{~mm}$ size sieve (Fritsch mesh) to remove small particles. The moisture content of the raw SCB was about $7 \mathrm{wt} \%$. The natural powder graphite $(\leq 20 \mu \mathrm{m}$; 99.99\%) was purchased from Sigma-Aldrich. The polyvinyl alcohol (molecular weight: 10,000-26,000; 86-89\% hydrolyzed; CAS: 9002-89-5) was purchased from Alfa-Easer. Analytical grade chemicals used for CNC extraction and GON preparation were purchased from Sigma-Aldrich and used without further purification.

\subsection{Preparation of $\mathrm{CNC}$}

CNC aqueous suspension was prepared from SCB by using the sulfuric acid hydrolysis process according to our previous works (El Miri et al., 2015a, b). Briefly, the ground SCB fibers were washed with distilled water for 1 hour at $60{ }^{\circ} \mathrm{C}$ under mechanical stirring. Then, the prewashed SCB fibers were treated three times with 4 wt $\% \mathrm{NaOH}$ solution at $80{ }^{\circ} \mathrm{C}$ for 2 
hours under stirring, and bleached with a solution made by equal parts of acetate buffer, aqueous chlorite (1.7 wt \% in water) and distilled water. The bleaching treatment was performed 4 times at $80{ }^{\circ} \mathrm{C}$, under mechanical stirring, during 4 hours for each one. Acid hydrolysis was achieved at $55{ }^{\circ} \mathrm{C}$ with $64 \mathrm{wt} \%$ sulfuric acid for 30 minutes under mechanical stirring. Then, the mixture was diluted with ice cubes to stop the reaction and was washed by successive centrifugations at $12000 \mathrm{rpm}$ at $15^{\circ} \mathrm{C}$ for 30 minutes at each step and dialyzed against distillated water until it reached neutral $\mathrm{pH}$. Afterward, the obtained $\mathrm{CNC}$ aqueous suspension was homogenized by the use of a probe-type ultrasonic homogenizer (Branson sonifier model 450) for 5 minutes in an ice bath. The concentration of the obtained CNC aqueous suspension was measured at $3.76 \mathrm{mg} / \mathrm{mL}$ (Figure 1). Finally, a small quantity of the homogenized CNC suspension was freeze-dried (Christ Alpha 2-4 LD Freeze Dryer) to obtain the $\mathrm{CNC}$ in solid form for characterizations.

\subsection{Preparation of GON}

GON aqueous suspension was prepared via chemical oxidation of natural graphite followed by sonication assisted water-phase exfoliation according to our previous works (El Achaby et al., 2012a, b; El Achaby et al., 2013a, b; El Achaby et al., 2014). Firstly, the graphite oxide (oxidized graphite) was prepared according to Hummers methods (Hummers \& Offeman, 1958). In this procedure, $\mathrm{H}_{2} \mathrm{SO}_{4}, \mathrm{NaNO}_{3}$ and $\mathrm{KMnO}_{4}$ were used to oxidize the graphite after which dilution and washing were performed with distilled water. Residual metallic ions were removed by the use of hydrogen peroxide and hydrochloric acid. The graphite oxide was then isolated through centrifugation and drying. To exfoliate graphite oxide into individual GON, the desired amount of graphite oxide was dispersed in water and then sonicated for 1 hour, resulting in yellow-brownish GON aqueous suspension with a concentration of $1.5 \mathrm{mg} / \mathrm{mL}$ (Figure 1). Finally, a small quantity of the obtained GON 
suspension was freeze-dried (Christ Alpha 2-4 LD Freeze Dryer) to obtain the GON in solid form for characterizations.

\subsection{Preparation of $C: G$ hybrid nanofiller}

For the preparation of the $\mathrm{C}: \mathrm{G}$ hybrid nanofiller, the as pre-prepared $\mathrm{CNC}$ and GON aqueous suspensions were used after adjusting their concentrations. Three C:G hybrids were prepared by varying the mass ratio of each material (2:1,1:1 and 1:2) and the three mixtures were prepared as follows: $15 \mathrm{~mL}$ of $\mathrm{CNC}$ aqueous suspension containing the desired amount of $\mathrm{CNC}$ was mixed with $35 \mathrm{~mL}$ of GON aqueous suspension containing the desired amount of GON, and the obtained mixtures of $\mathrm{CNC}$ and GON were stirred for 15 minutes and sonicated for 2 hours (Ultrasonic System, SharperTek ${ }^{\circledR}$ Stamina XPTM, 50 W) at room temperature, resulting in well-homogenized C:G suspensions with a total concentration of $1.5 \mathrm{mg} / \mathrm{mL}$

(Figure 1). The samples were coded as C:G-2:1, C:G-1:1 and C:G-1:2 for C:G hybrids at mass ratio of $2: 1,1: 1$ and 1:2, respectively. It should be noted that $C: G$ hybrids in powdered form were also prepared for characterizations, using the freeze-drying process.

\subsection{Preparation of PVA nanocomposite films}

Nanocomposite films of PVA-CNC, PVA-GON and PVA-C:G were prepared using the solvent casting method. The loading level of $\mathrm{CNC}, \mathrm{GON}$ and $\mathrm{C}: \mathrm{G}$ hybrid nanofillers in nanocomposites was fixed at $5 \mathrm{wt} \%$. For the PVA-C:G nanocomposite films, three different samples were prepared using the three pre-prepared $\mathrm{C}: \mathrm{G}$ hybrid nanofillers (C:G-2:1, C:G-1:1 and C:G-1:2). Three similar PVA solutions were prepared by dissolving $1.425 \mathrm{~g}$ (95 wt $\%$ in nanocomposites) of PVA in $20 \mathrm{~mL}$ of water, under continuous stirring, for 30 minutes at 90 ${ }^{\circ} \mathrm{C}$. The solutions were then cooled to room temperature and allowed to stand in order to remove any air bubbles. Then, each PVA solution was mixed with each pre-prepared C:G suspension (C:G-2:1, C:G-1:1 and C:G-1:2). It must be noted that each C:G suspension contains a total solid mass of $75 \mathrm{mg}$ suspended in $50 \mathrm{~mL}$ of water (see above), which 
corresponds to $5 \mathrm{wt} \%$ in regard to the total mass of nanocomposites. Next, each PVA-C:G mixture was continuously stirred for 2 hours at room temperature to get a homogeneous mixture of well-dispersed C:G hybrid in PVA solution. Afterward, the final PVA-C:G mixtures were poured into Petri dishes, and the water evaporated at room temperature for 2 days. Finally, the obtained films were dried for 2 hours at $80{ }^{\circ} \mathrm{C}$ for complete removal of water. The films were coded as PVA-C:G-2:1, PVA-C:G-1:1, and PVA-C:G-1:2. Exactly the same procedure was applied to prepare films of neat PVA and PVA nanocomposites containing only CNC or GON; and the films were coded as PVA, PVA-CNC, PVA-GON.

Table 1: List of some hybrid nanofillers recently used as reinforcement for high performance polymer nanocomposites.

\begin{tabular}{|c|c|}
\hline Hybrid nanofiller & Reference \\
\hline Graphene/carbon nanotubes (CNT) & $\begin{array}{l}\text { (Dhibar et al., 2014; Chatterjee et al., 2012; Zhang } \\
\text { et al., 2012; Li et al., 2015; Shen, Pei, Liu, \& Fu, } \\
\text { 2014; Yi, Yoo, Mahapatra, Kim, \& Cho, 2014; } \\
\text { Zhang et al., 2013) }\end{array}$ \\
\hline Graphene/SiC nanowires & (Wang et al., 2014a) \\
\hline Graphene/nanoclay & (Wang et al., 2014b) \\
\hline Graphene $/ \mathrm{Fe}_{3} \mathrm{O}_{4}$ nanoparticles & (Zhang et al., 2014) \\
\hline Graphene/boehmite & (Yuan et al., 2014) \\
\hline layered double hydroxide /CNT & (Huang et al., 2010) \\
\hline CNT/ fullerene-like tungsten disulfide & (Naffakh, Diez-Pascual, Marco, \& Ellis, 2012) \\
\hline CNT/nanoclay & $\begin{array}{l}\text { (Tang et al., 2009; Tang et al., 2012; Pradhan, Roy, } \\
\text { Srivastava, \& Saxena, 2015) }\end{array}$ \\
\hline Nanoclay $/ \mathrm{Al}_{2} \mathrm{O}_{3}$ nanoparticles & (Jose \& Thomas, 2014a, b) \\
\hline CNC/Ag nanoparticles & $\begin{array}{l}\text { (George et al., 2012; George et al., 2014; Yu et al., } \\
\text { 2014; Xu, Yang, Xing, Yang, \& Wang, 2013; } \\
\text { Fortunati et al., 2013a) }\end{array}$ \\
\hline
\end{tabular}

\subsection{Characterization techniques}

The zeta potential measurements were carried out using a Malvern Zetasizer Nano ZS

instrument. Measurements were made at $23{ }^{\circ} \mathrm{C}$ using $1 \mathrm{~mL}$ of diluted suspensions $(0.25$ $\mathrm{mg} / \mathrm{mL}$ ) of $\mathrm{CNC}, \mathrm{GON}$ and $\mathrm{C}: \mathrm{G}$ samples. Immediately before being analyzed, diluted suspensions were sonicated for 5 minutes in an ultrasonic bath (Ultrasonic System, SharperTekVR Stamina XPTM, $50 \mathrm{~W}$ ) and then transferred to a folded capillary cell (DTS 
1060, Malvern Instruments). Atomic Force Microscopy (AFM) measurements were carried out using a Veeco Dimension ICON. Tapping mode was used to capture height images at a scan rate of $1.5 \mathrm{~Hz}$. Samples for AFM observations were prepared by depositing a droplet of diluted suspensions onto freshly cleaved mica sheets, and allowing the solvent to dry in air. The morphology observation was performed using a Scanning Electron Microscope (SEM) (FEI, Quanta 200-ESEM) operating at an accelerating voltage of $20 \mathrm{kV}$. Immediately before being analyzed, samples were coated by a thin conductive carbon layer to help improve SEM observations. Fourier Transform Infrared Spectroscopy (FTIR) measurements were performed on an ABB Bomem FTLA 2000 spectrometer equipped with a Golden Gate single attenuated total reflection (ATR) cell. The experiments were carried out in the range of $4000-400 \mathrm{~cm}^{-1}$ with a $4 \mathrm{~cm}^{-1}$ resolution and an accumulation of 32 scans. The FTIR spectra were taken in the transmittance mode. Thermogravimetric Analyses (TGA) were carried out under nitrogen atmosphere at a heating rate of $10^{\circ} \mathrm{C} \cdot \mathrm{min}^{-1}$ from 25 to $700{ }^{\circ} \mathrm{C}$, using a TGA-Q500 (TA Instrument). Differential Scanning Calorimetry (DSC) was carried out under nitrogen gas with a $10{ }^{\circ} \mathrm{C} \cdot \mathrm{min}^{-1}$ heating rate from $-50{ }^{\circ} \mathrm{C}$ to $250{ }^{\circ} \mathrm{C}$, using a DSC-Q100 (TA Instrument). Tensile tests were performed using an Instron $8821 \mathrm{~S}$ tensiometer. The tensile specimens were cut in rectangular shapes with dimensions of $80 \mathrm{~mm}$ in length and $10 \mathrm{~mm}$ in width. The gauge length was fixed at $30 \mathrm{~mm}$ and the speed of the moving clamp was $5 \mathrm{~mm} / \mathrm{min}$. All tests were carried out on a minimum of five samples and the reported results are average values.

Moisture uptake measurements were carried out according to the method used by Soykeabkaew et al. (2012). Briefly, strips with specific dimensions (10 $\mathrm{mm} \times 40 \mathrm{~mm})$ were dried at $105{ }^{\circ} \mathrm{C}$ for 2 hours in an oven. After being weighted, the dried films were inserted in a climatic chamber containing a saturated $\mathrm{NaCl}$ solution with controlled relative humidity (RH) of $75 \pm 0.5 \%$ at $25{ }^{\circ} \mathrm{C}$. Thereafter, the samples were removed at specific intervals (each 
hour) over the duration of 6 hours and weighted using a digital balance. The moisture uptake of the samples was calculated as follows:

Moisture uptake $(\%)=\frac{\text { Mt }-\mathrm{M} 0}{\mathrm{Mo}} \times 100$.

Where $\mathrm{M}_{\mathrm{t}}$ and $\mathrm{M}_{0}$ are the weights of the sample after $t_{\min }$ exposure to $75 \% \mathrm{RH}$ and of the dried sample before being inserted in the climatic chamber, respectively.

\section{Results and discussions}

\subsection{Characterization of nanofillers}

In the present work, pre-prepared $\mathrm{CNC}$ and $\mathrm{GON}$ aqueous suspensions were used as starting materials to produce three $\mathrm{C}: \mathrm{G}$ hybrid nanofillers at different mass ratios $(2: 1,1: 1$ and 1:2). Figure 1 shows photographs of aqueous suspensions of CNC, GON, C:G-2:1, C:G-1:1 and C:G-1:2 obtained by sonication process. These photographs were taken 15 days after their preparation. The measured zeta potential of these suspensions is also illustrated in Figure 1. As seen in this Figure, the CNC aqueous suspension showed a good stability, in which a white gel appearance was observed. It is well known that, after their homogenization, CNC are stable in water because of their surface functionalities and the ability of the water solvent and surface groups to counterbalance the attractive hydrogen-bond interactions exerted by the abundant hydroxyl groups on the surface of CNC (El Miri et al., 2015a, b). Additionally, the zeta potential of the as-prepared $\mathrm{CNC}$ suspension showed a value of $-61.3 \mathrm{mV}$ (Figure 1). Consequently, the CNC suspension was considered stable because the absolute value was higher than $25 \mathrm{mV}$ (El Miri et al., 2015a, b). On the other hand, suspended individual nanosheets of GON were obtained by intense sonication in water of completely oxidized natural graphite (graphite oxide) (El Achaby et al., 2012a, b; El Achaby et al., 2013a, b; El Achaby et al., 2014). Remarkably, it should be noted that the GON suspension exhibited strong and long-term stability in water (Figure 1). This was due to the hydrophilic oxygen groups attached to the GON's basal plane and edges (Rodríguez-González et al., 2012; Szabo 
et al., 2006). The zeta potential of GON suspension was measured at $-41.3 \mathrm{mV}$, which is comparable to previous works (Chen et al., 2014; Li, Muller, Gilje, Kaner, \& Wallace, 2008). By mixing both $\mathrm{CNC}$ and GON aqueous suspensions, at different mass ratios, via stirring and sonication process, stable mixtures were obtained (Figure 1). This was unsurprisingly because the hydrophilic nature of both kinds of nanomaterials and their good interfacial compatibility. The values of the measured zeta potential of these mixtures were found to be $-44.8,-39.3$ and $-37.7 \mathrm{mV}$ for $\mathrm{C}: \mathrm{G}-2: 1, \mathrm{C}: \mathrm{G}-1: 1$ and $\mathrm{C}: \mathrm{G}-1: 2$ samples, respectively. Remarkably, the zeta potential of CNC suspension $(-61.3 \mathrm{mV})$ was reduced after its mixture with GON suspension, confirming that interfacial interactions throughout hydrogen bonding occurred in the $\mathrm{C}$ : G hybrid mixtures.
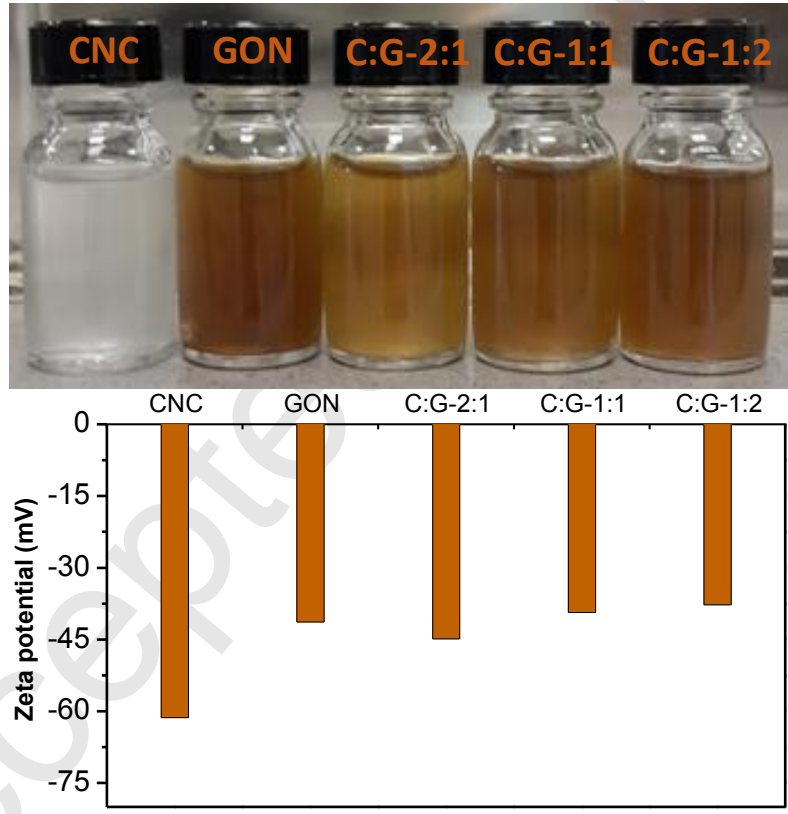

Figure 1: Photographs of aqueous suspensions and zeta potential values of $\mathrm{CNC}, \mathrm{GON}$ and $\mathrm{C}: \mathrm{G}$ hybrids (C:G-2:1, C:G-1:1 and C:G-1:2).

AFM observations were used to investigate the morphology and dimensions of CNC and GON nanomaterials and their C:G hybrid nanofillers. Examples of the obtained AFM images are illustrated in Figure 2. For CNC, the AFM image showed that the as-extracted CNC had needle-like nanoparticles, confirming that their extraction from the treated SCB was 
successful. Furthermore, the average diameter and length of the as-extracted CNC were found to be $5 \pm 1.1 \mathrm{~nm}$ and $275 \pm 73 \mathrm{~nm}$, respectively. These results coincide with those reported by Teixeira et al. (2011), especially in relation to the geometry and dimensions of CNC obtained from SCB by $6 \mathrm{M}$ sulfuric acid hydrolysis. On the other hand, the AFM images of the GON revealed the presence of irregular shaped individual nanosheets with uniform thickness and different lateral dimensions (El Achaby et al., 2014), an example of an individual nanosheet is shown in Figure 2. The lateral dimensions of nanosheets range from $\sim 100 \mathrm{~nm}$ to $\sim 2 \mu \mathrm{m}$ while the thickness was measured at $\sim 0.9 \mathrm{~nm}$ (El Achaby et al., 2012a; El Achaby et al., 2014).

CNC
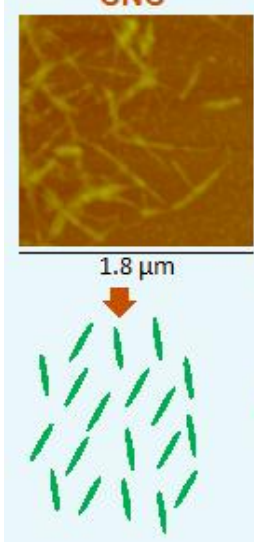

GON
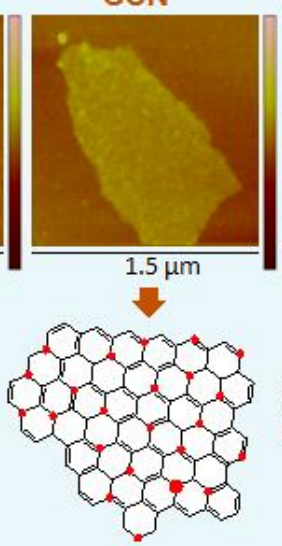

C:G hybrid
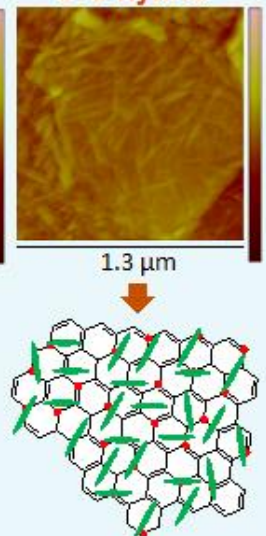

Figure 2: Tapping mode AFM images and schematic illustrations of CNC, GON and C:G hybrid (C:G-1:2) (the red dots are the oxygen containing groups in GON).

For the AFM image of $\mathrm{C}: \mathrm{G}$ hybrid nanofiller (C:G-1:2), one can see that the surface of GON has become totally and densely covered with randomly arranged CNC (Figures 2). The exact dimensions of $\mathrm{C}: \mathrm{G}$ hybrid nanofillers cannot be measured accurately. The size of these nanofillers was controlled by the initial size of $\mathrm{CNC}$ and GON, and the thickness cannot be measured because the CNC were attached to the surfaces and edges of GON, forming a 3-D interconnected network microstructure, as schematically illustrated in the bottom of Figure 2. Previous works investigating the graphene-based hybrid nanofillers demonstrated that, in all cases, the graphene nanosheets were decorated after their combination with other nanomaterials such as aramid nanofibers (Fan, Shi, Zhang, Wang, \& Yin, 2012), $\mathrm{Fe}_{3} \mathrm{O}_{4}$ 
nanoparticles (Zhang et al., 2014), CNT (Chatterjee et al., 2012; Zhang et al., 2012), SiC-

nanowires (Wang et al., 2014a), and boehmite (Yuan et al., 2014), forming a new

interconnected microstructure. This behavior was ascribed to the 2-D flat surface of graphene,

which is exposed to absorb other compatible nanosized materials. Herein the CNC and GON

are compatible nanomaterials because they have similar surface functionalities, especially the oxygen containing groups, resulting in the formation of such hybrid nanofiller.

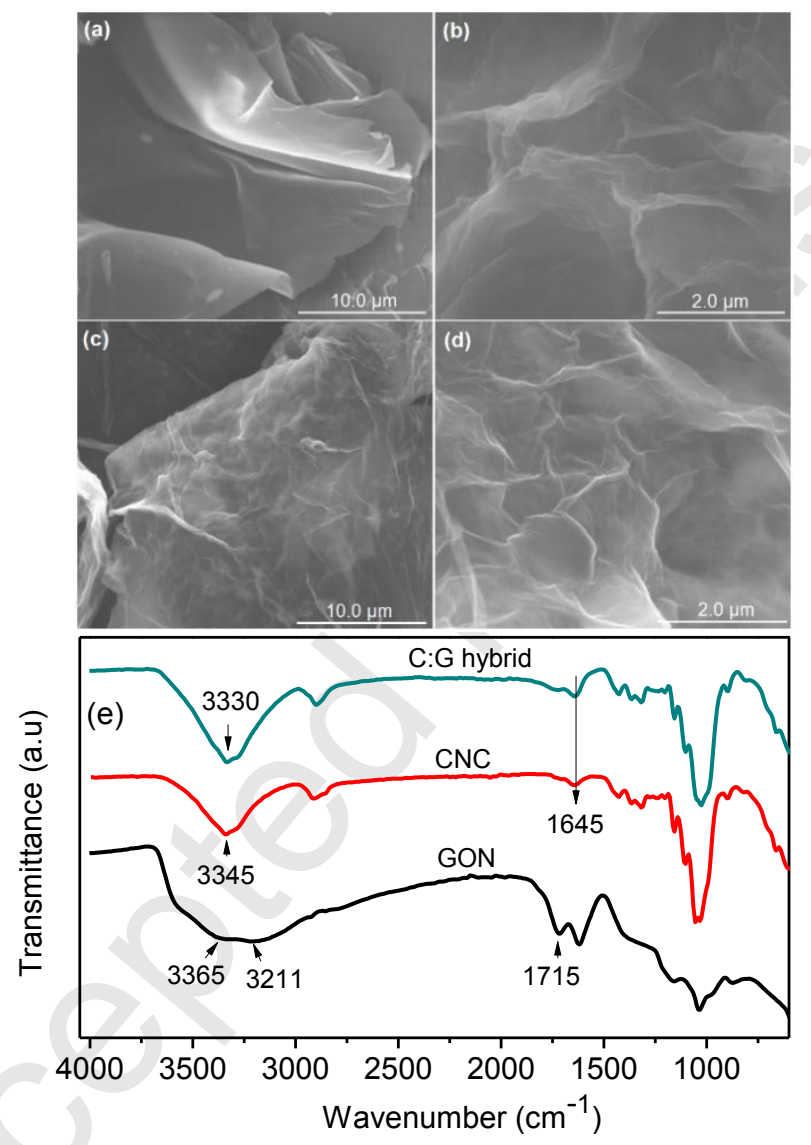

Figure 3: MEB images of (a,b) GON and (c,d) C:G hybrid (C:G-1:1) and (e) FTIR spectra of CNC, GON and C:G hybrid (C:G-1:1).

Figures 3a-d present SEM images of the freeze dried GON and the C:G hybrid (C:G1:1). It is clearly evident that the exfoliated GON exist as flakes (agglomerated sheets) with a smooth surface and distinct bent edges (Figure 3a,b). However, in the C:G hybrid nanofiller, CNC appear to be homogeneously dispersed among GON flakes (Figures 3c,d). Additionally, the SEM image of C:G hybrid at low magnification shows the formation of an interconnected 
network between GON and CNC, leading to a 3-D like network microstructure (Figure 3d).

This morphology was also observed in other hybrids prepared by the combination of 1-D and 2-D nanomaterials, such as CNT/clay platelets (Pradhan et al., 2015), LDH/CNT (Zhao, Zhang, Huang, \& Wei, 2012), and graphene/CNT (Tang et al., 2012).

Figure 3e shows FTIR spectra of CNC, GON and C:G hybrid (C:G-1:1). In the FTIR spectrum of CNC, the peaks found at 2914 and $1369 \mathrm{~cm}^{-1}$ are assigned to $\mathrm{C}-\mathrm{H}$ stretching and bending vibrations. The peaks observed at 1429 and $1055 \mathrm{~cm}^{-1}$ are assigned to the vibrations of $\mathrm{O}-\mathrm{H}$ and C-O, respectively. The broad band centered at $3345 \mathrm{~cm}^{-1}$ is associated with $\mathrm{O}-\mathrm{H}$ bonds in hydroxyl groups. The peak at $1645 \mathrm{~cm}^{-1}$ is associated with intramolecular hydrogen bonds (El Miri et al., 2015a; Valentini et al., 2013). For the GON spectrum, the bands at 3365 and $3211 \mathrm{~cm}^{-1}$ are associated to the stretching of $\mathrm{O}-\mathrm{H}$ bonds in hydroxyl groups. The band at $1715 \mathrm{~cm}^{-1}$ is attributed to the $\mathrm{C}=\mathrm{O}$ carbonyl stretching, and the bands at 1038 and $973 \mathrm{~cm}^{-1}$ are associated to the epoxide groups $\mathrm{C}>\mathrm{O}$ vibration (El Achaby et al., 2012a; El Achaby et al., 2014). Looking at the $C: G$ hybrid nanofiller, the bands at $3345 \mathrm{~cm}^{-1}, 3365$ and $3211 \mathrm{~cm}^{-1}$ that are associated to the hydroxyl groups in $\mathrm{CNC}$ and GON spectra, respectively, were shifted to a new band at $3330 \mathrm{~cm}^{-1}$ in the spectrum of the $\mathrm{C}: \mathrm{G}$ hybrid nanofiller. Additionally, the band at $1715 \mathrm{~cm}^{-1}$ that is associated to the carbonyl groups observed in GON spectrum was overlapped with that observed at $1645 \mathrm{~cm}^{-1}$ in $\mathrm{C}: \mathrm{G}$ spectrum, which is associated to the intramolecular hydrogen bonds in CNC. These results confirm that strong hydrogen interactions occur in the C:G hybrid nanofillers (Valentini et al., 2013). Recently, successful combinations of $\mathrm{CNC}$ and GON in the form of hybrid composite films have been reported in the literature, by taking into account the hydrogen interaction and the interfacial compatibility between CNC and GON surfaces (Chen et al., 2014; Sadasivuni et al., 2015; Valentini et al., 2013). Herein, the combination of CNC and GON in a hybrid nanofiller should act as a stronger reinforcing agent for polymers causing synergistic effects. 


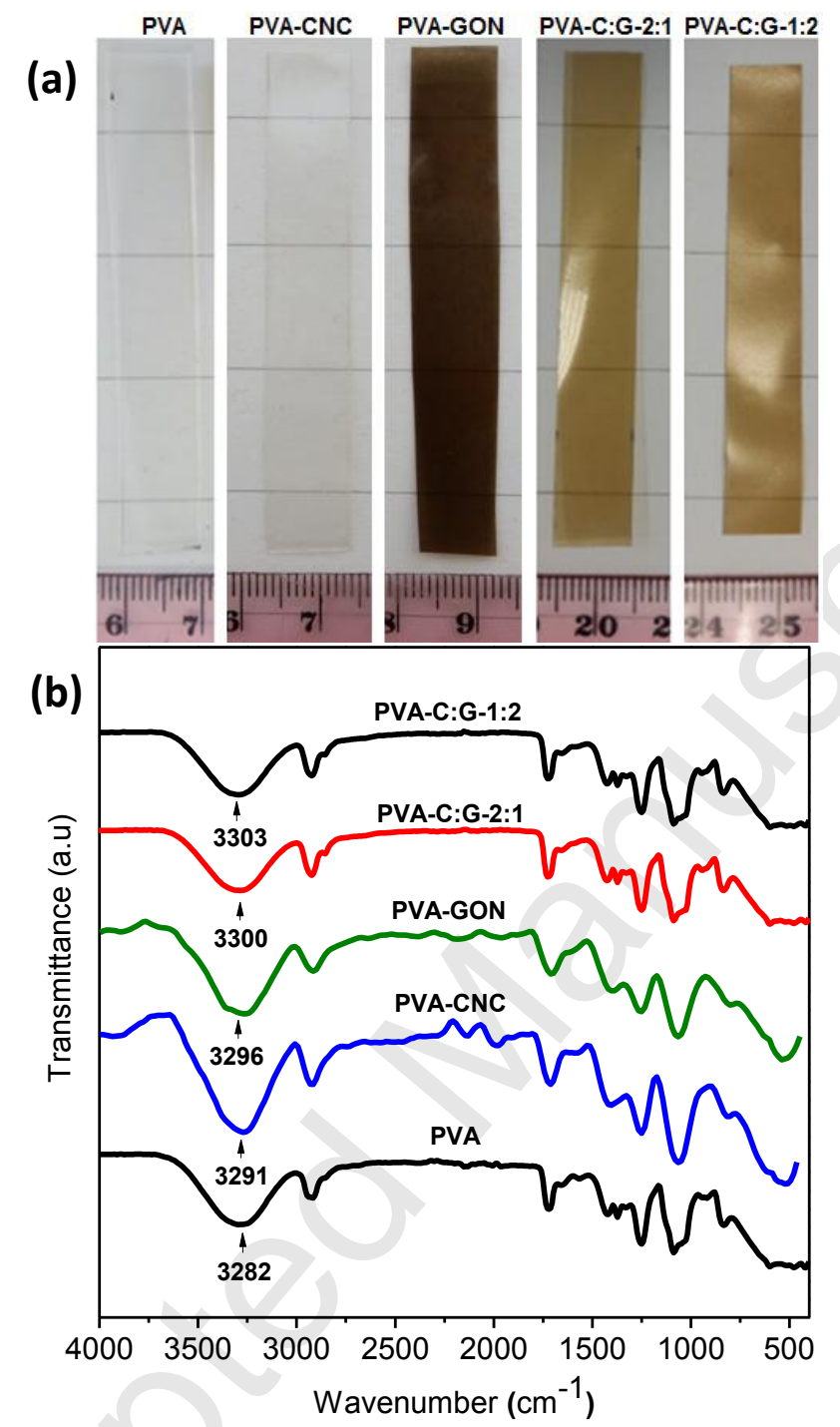

Figure 4: (a) Digital images and (b) FTIR spectra of neat PVA and its nanocomposite films with CNC, GON and C:G hybrid (C:G-2:1 and C:G-1:2).

The mixing of the PVA polymer with $\mathrm{CNC}, \mathrm{GON}$ and C:G hybrid nanofillers in water was easily achieved in controlled conditions, enabling the formation of a homogeneous and stable aqueous mixtures. By casting all mixtures on plastic dishes and evaporating of the

341 images of the produced films of unloaded PVA, PVA-CNC, PVA-GON and PVA-C:G (PVA-

C:G-2:1 and PVA-C:G-1:2). As shown in these images, the visual transparency of PVA was not affected by the addition of CNC and a clear dark color was observed for PVA-GON 
nanocomposite film. In consequence, an intermediate color was observed for PVA-C:G films.

345 This behavior is mainly associated with the initial color of each nanofiller suspension (Figure

346 1). This result indicated that the components of each formulation were well mixed in the

347 chosen conditions of the preparation. We noted that the thickness of these films was

348 adjustable by controlling the amount of the solution used for the casting technique (El Miri et 349 al., 2015a, b).

(a)
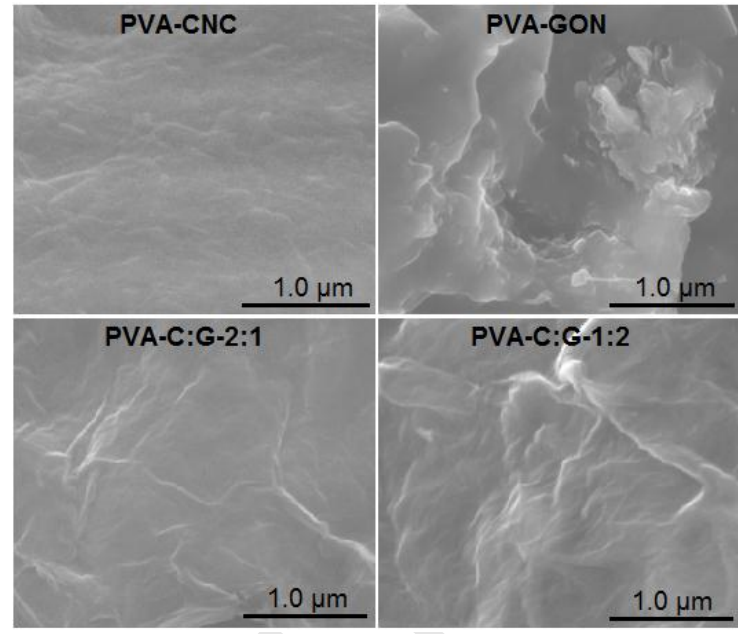

(b)

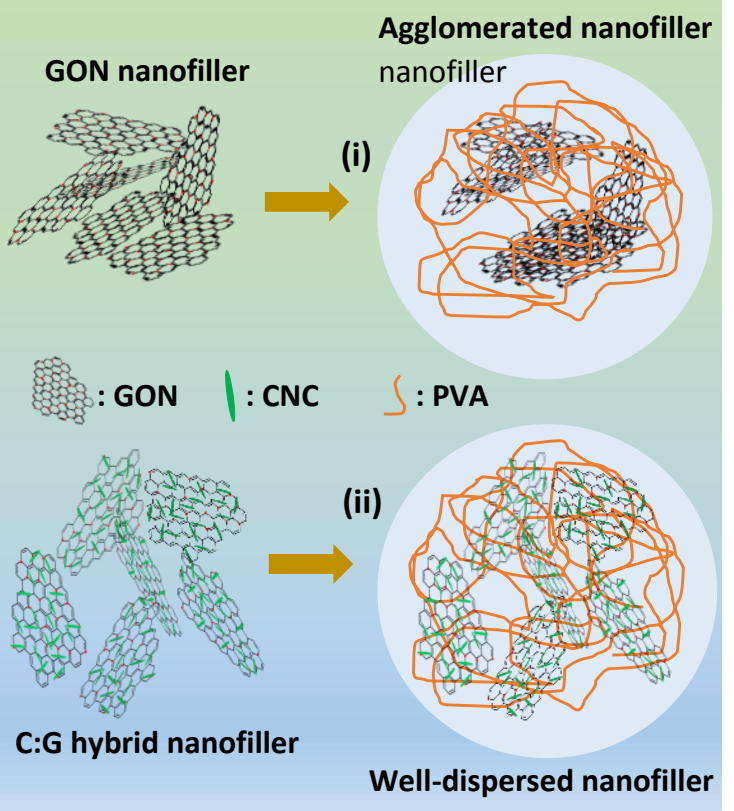

Figure 5: (a) SEM micrographs of PVA nanocomposites with CNC, GON and C:G 
FTIR spectra of PVA and its nanocomposite are shown in Figure 4b. It is well known that

355

356

357

the $-\mathrm{OH}$ band is sensitive to hydrogen bonding and can be compelled to a shifted wavenumber in FTIR spectra. As shown in Figure 4b, the addition of the C:G hybrid nanofiller within the PVA matrix resulted in shifting the hydroxyl band in the range of 3500$3000 \mathrm{~cm}^{-1}$, indicating the existence of hydrogen bonding interactions between the oxygen containing functional groups on the surface of C:G hybrid nanofiller and the hydroxyl groups on the PVA macromolecular chains. This trend was also observed in CNC- or GON-filled PVA nanocomposite films (Figures 4b), in which hydrogen bonding interactions can occur between the oxygen functional groups of each nanofiller with PVA chains. Similar trends have been reported for CNC-filled PVA (Fortunati et al., 2013b; Peresin, Habibi, Zoppe, Pawlak, \& Rojas, 2010), GON-filled PVA (Huang et al., 2012), and Ag-decorated CNC hybrid nanofiller filled PVA (Fortunati et al., 2013a) nanocomposite films.

Figure 5a shows SEM images of the cryofractured surface of PVA-CNC, PVA-GON, PVA-C:G-2:1 and PVA-C:G-1:2 nanocomposite films. From these images, the PVA-CNC nanocomposite show a homogenous structure in which the CNC are well dispersed with small aggregates, while the GON showed large aggregates in PVA-GON nanocomposite. The aggregation tendency of GON was mainly due to the existence of strong hydrogen bonding between the surface hydroxyl groups of GON, and consequently the sheet-sheet interaction becomes dominant over the sheet-matrix interaction. This type of aggregation may lead to the formation of thicker flakes instead of nanosheets within the polymer matrix, as schematically proposed in the Figure 5b(i) for PVA-GON nanocomposite system. For PVA-C:G nanocomposites, the SEM micrographs clearly indicate that the C:G nanofillers are welldispersed within PVA matrix (the well-dispersed white lines are the GON and CNC) (Figure 5a). No visible nanofiller agglomerates were observed in the nanocomposites. It is believed that the $\mathrm{CNC}$ adsorbed on the GON surface could inhibit the sheet-to-sheet aggregations of 
GON and that the hybrid nanofiller-polymer matrix interfacial adhesion could also be improved. In these nanocomposite films, a 3D interconnected network is assumed to be formed. The special morphology of C:G hybrid nanofiller and its functionalized surface ensure a good homogeneous dispersion within the PVA matrix, as proposed in the scheme of Figure 5b(ii) for PVA-C:G nanocomposite. This was mainly the result of strong interactions between the macromolecular chains of the PVA and the C:G hybrid nanofiller via hydrogen bonding. Consequently, the excellent dispersion of $\mathrm{C}: \mathrm{G}$ hybrid nanofillers within the polymer matrix was directly correlated with its effectiveness in improving the properties of nanocomposite films.

\subsection{Thermal properties of PVA nanocomposite films}

The effect of nanofillers on glass transition $\left(T_{g}\right)$ and melting $\left(T_{m}\right)$ temperatures of PVA is shown in Figures 6a,b, which were determined from DSC analysis. From the obtained results, it is clear that these thermal parameters were influenced by the addition of $5 \mathrm{wt} \%$ CNC (PVACNC), $5 \mathrm{wt} \%$ GON (PVA-GON) and $5 \mathrm{wt} \% \mathrm{C}: \mathrm{G}$ hybrid nanofillers at various mass ratios (PVA-C:G-2:1, PVA-C:G-1:1 and PVA-C:G-1:2). The $T_{g}$ illustrated in Figure 6a increases from $48.50{ }^{\circ} \mathrm{C}$ for neat PVA to 52.62, 53.69 and 56.24 ${ }^{\circ} \mathrm{C}$ for PVA-C:G-2:1, PVA-C:G-1:1 and PVA-C:G-1:2 nanocomposite films, respectively. Additionally, the increase of $T_{g}$ is accompanied by an increase of $T_{m}$ from $191.70{ }^{\circ} \mathrm{C}$ for neat PVA to $192.93,193.19$ and 194.07 ${ }^{\circ} \mathrm{C}$ for PVA-C:G-2:1, PVA-C:G-1:1 and PVA-C:G-1:2, respectively (Figure $6 \mathrm{~b}$ ). These observed values for $T_{g}$ and $T_{m}$ were superior to those observed for PVA-CNC $\left(49.10{ }^{\circ} \mathrm{C}\right.$ and 192.2 ${ }^{\circ} \mathrm{C}$ ) and PVA-GON $\left(50.79{ }^{\circ} \mathrm{C}\right.$ and $\left.192.4{ }^{\circ} \mathrm{C}\right)$. Consequently, the increase in $T_{g}$ and $T_{m}$ suggests that the mobility of PVA macromolecular chains was inhibited, which results from the formation of a cross-linking network between the PVA and C:G hybrid nanofiller through hydrogen bonds between the oxygen-containing functional groups of nanofiller and the hydroxyl groups of PVA chains (Huang et al., 2012). This effect was more pronounced in 
nanocomposites containing C:G hybrid nanofiller in comparison to those containing only

$\mathrm{CNC}$ or GON, and can be ascribed to the synergistic effect generated from the hybrid nanofiller. This effect is more important for the hybrid nanofiller containing the high amount of GON (C:G-1:2), because the PVA-C:G-1:2 exhibited the higher $T_{g}$ and $T_{m}$ in comparison to PVA-C:G-1:1 and PVA-C:G-2:1.
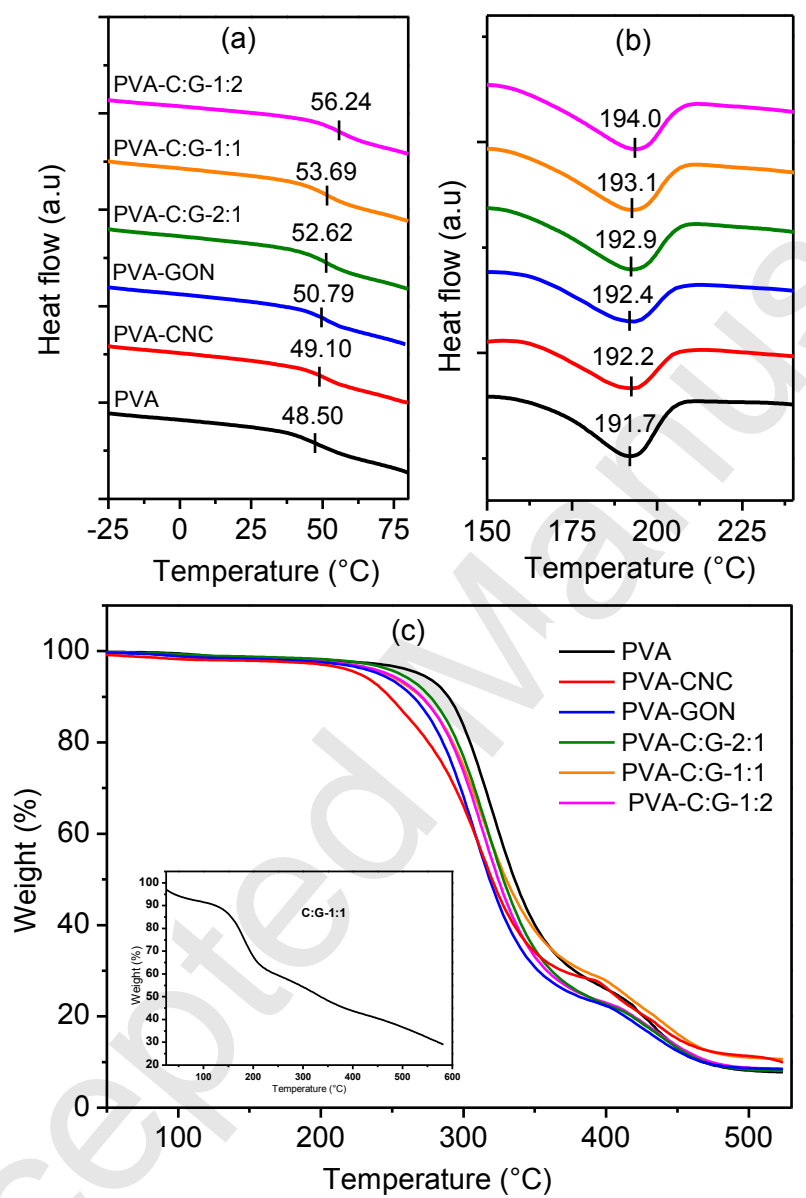

Figure 6: (a) Glass transition temperature and (b) melting temperature obtained from DSC curves and (c) TGA curves of PVA and its nanocomposites films with CNC, GON and C:G (C:G-2:1, C:G-1:1 and C:G-1:2) hybrid nanofillers. The TGA curve of the C:G-1:1 hybrid is shown in the inset of (c).

Figure $6 \mathrm{c}$ shows the TGA curves of neat PVA and its nanocomposites. It is clear that the onset temperatures $\left(T_{\text {onset }}\right)$ of nanocomposites are almost identical and slightly lower than that observed for neat PVA $\left(T_{\text {onset }}=269{ }^{\circ} \mathrm{C}\right)$. Herein, the $T_{\text {onset }}$ is reported as the temperature corresponding to $5 \%$ weight loss $\left(T_{\text {onset }}=T_{5 \%}\right)$. However, the $T_{\text {onset }}$ of 
nanocomposites containing C:G-2:1, C:G-1:1 and C:G-1:2 was observed at 256, 244 and $246{ }^{\circ} \mathrm{C}$, respectively. This behavior was due to the thermal instability of dispersed C:G hybrid nanofillers; an example for C:G-1:1 is shown in the inset of Figure 6c. Importantly, the weight loss observed for $\mathrm{C}: \mathrm{G}$ hybrid nanofiller around $250{ }^{\circ} \mathrm{C}(\approx 45$ $\%$ ) is absent in the nanocomposite samples, suggesting a good interaction between the oxygen functional groups of the $\mathrm{C}: \mathrm{G}$ nanofillers and the macromolecular chains of PVA polymer. Comparatively, in nanocomposite films containing only CNC or GON, the $T_{\text {onset }}$ was lower than that of all nanocomposites containing C:G hybrid nanofillers $\left(226{ }^{\circ} \mathrm{C}\right.$ for $\mathrm{CNC}$ and $240{ }^{\circ} \mathrm{C}$ for $\mathrm{GON}$ ), which was ascribed to the fine dispersion of the C:G hybrid nanofillers within the PVA polymer, thus confirming that the synergistic effect between CNC and GON existed in PVA-C:G nanocomposites.

\subsection{Mechanical properties of PVA nanocomposite films}

The mechanical properties of PVA and its nanocomposite films with different nanofillers were investigated by uni-axial tensile testing. Typical stress-strain curves of all films are presented in Figures $7 \mathrm{a}, \mathrm{b}$ and the measured mechanical parameters are illustrated in Figures 7c-f. From these data, it can be seen that all nanocomposites containing C:G hybrid nanofillers (C:G-2:1, C:G-1:1 and C:G-1:2) exhibited superior mechanical properties than those observed for nanocomposites containing CNC or GON nanofillers, thus confirming that a unique synergistic effect of the C:G hybrid nanofillers on the reinforcing of the PVA was clearly observed. For example, the PVA-C:G-1:2 nanocomposite film exhibited a Young's modulus of $3639.48 \mathrm{MPa}$ and an ultimate tensile strength of 111.45 MPa, which correspond to $320 \%$ and $124 \%$ increases, respectively, in regard to neat PVA. In contrast, the Young's modulus and tensile strength of the PVA-CNC nanocomposite are increased only by 77 and $12 \%$, respectively, as compared to neat PVA, and they are increased by 137 and $53 \%$ in the case of PVA-GON nanocomposite. These results for CNC- or GON-based nanocomposite 
films were comparable with those already reported in the literature (Fortunati et al., 2013b;

Xu et al., 2009; Xu et al., 2013; Zhang et al., 2014).
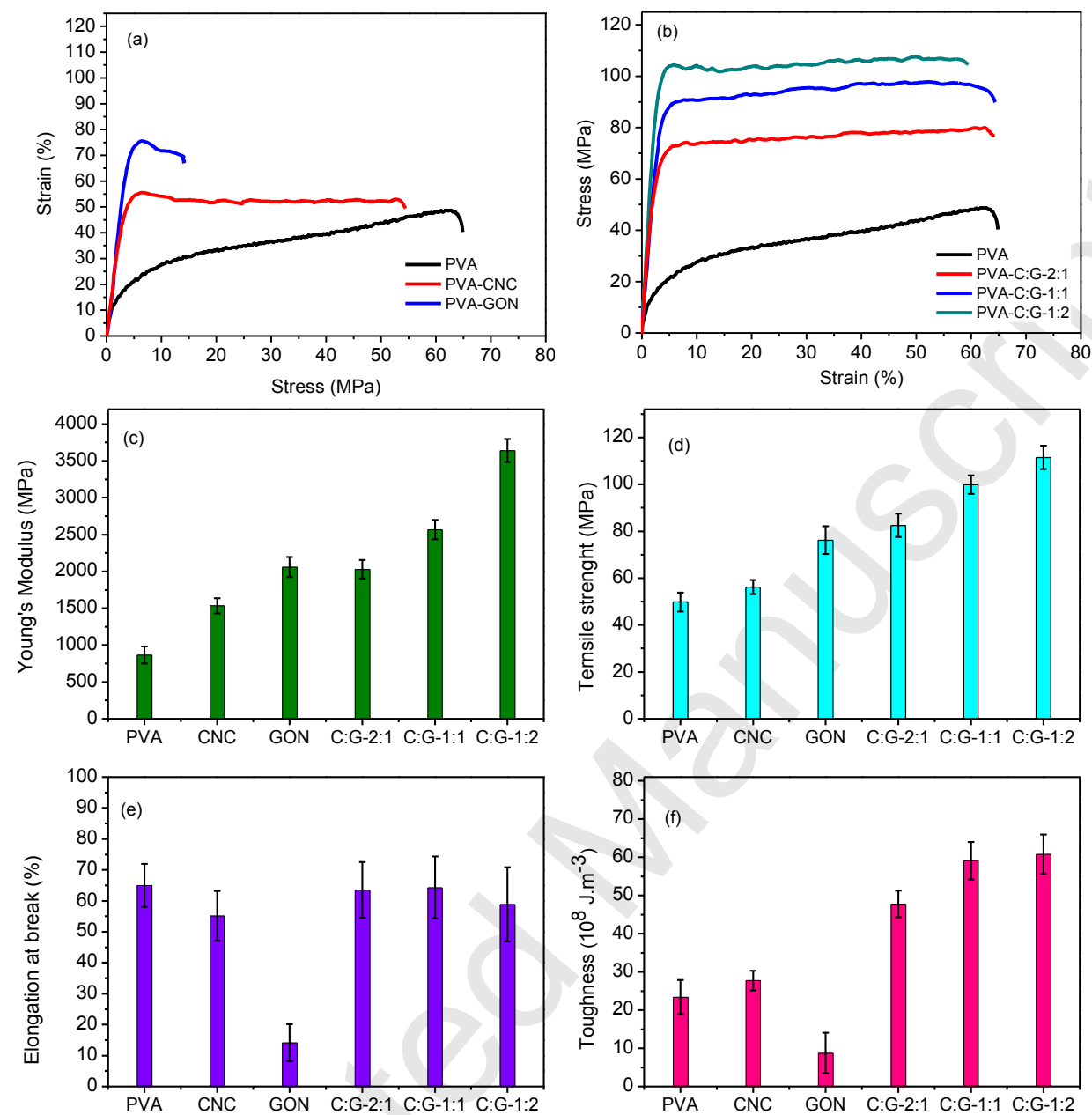

Figure 7: $(a, b)$ Typical stress-strain curves of PVA and its nanocomposites with CNC,

GON and C:G (C:G-2:1, C:G-1:1 and C:G-1:2) hybrid nanofillers, and plot of (c) Young's

modulus, (d) tensile strength, (e) elongation at break and (f) toughness (T) as function of

nanofillers.

Consequently, compared with $\mathrm{CNC}$ or GON, the C:G hybrid nanofiller showed better

performance in reinforcement of PVA nanocomposite, at the same loading level ( $5 \mathrm{wt} \%)$. This

is because of the synergetic effect induced by the combination of CNC and GON. Such

synergistic interactions resulted in the formation of an interconnected network structure,

which explains the very large increase in tensile properties of the PVA matrix. In the GON 
agglomeration phenomenon of nanosheets (Figure 5b(i)) (Jose et al., 2015; Xu et al., 2009;

Zhang et al., 2015). These agglomerates may prevent an efficient transfer of load to the

nanosheet and may cause a decrease in the aspect ratio. As discussed above, in the C:G hybrid nanofiller, the surface of GON had become decorated with CNC, which could have inhibited the sheet-to-sheet aggregations of GON (Figure 5b(ii)). Also, the interfacial adhesion between the $\mathrm{C}: \mathrm{G}$ hybrid nanofiller and the polymer matrix could be improved. In consequence, the C:G hybrid nanofiller network acts as an efficient reinforcement in the parent system, which provides superior tensile properties to the nanocomposites. In this case, effective stress transfer occurred from the polymer chains to the dispersed hybrid nanofiller, which provided additional strength to the nanocomposites (George et al., 2014). Similar trends were observed by Zhang et al. (2012) in GON/CNT hybrid nanofiller reinforced PVA nanocomposites, which were attributed to the synergistic effect phenomenon that was generated from the combination of GON and CNT.

Interestingly, the elongation at break of the PVA was not largely affected by the addition of different C:G hybrid nanofillers (C:G-2:1, C:G-1:1 and C:G-1:2). These results indicated that the as-developed PVA-C:G nanocomposite films are ductile materials, as the toughness of PVA-C:G nanocomposites was largely improved in comparison with the neat PVA (Figure 7f. This is unusual, as GON-filled nanocomposites become brittle materials with a reduced elongation at break (Figure 7e). Recently, it was demonstrated that the polymer matrix cannot lose its ductility when a hybrid nanofiller is added (George et al., 2014; Pradhan et al., 2015; Wang, Tian, \& Zhang, 2010; Xu et al., 2013). The research group of George et al. (2014) demonstrated that the presence of Ag nanoparticles on the surface of CNC helps the polymer to keep its ductility, because the Ag nanoparticles can act as a physical crosslink between the CNC and polymer chains, thus helping polymer chains to move and can keep its elongation properties, with improvement of the other mechanical 
481

482

483

484

485

486

487

488

489

490

491

492

493

494

495

496

497

498

499

500

501

502

503

504

properties. Herein, PVA chains can form hydrogen bonds with CNC rather than with GON, because the surface of GON is totally and densely covered with CNC, as shown by AFM and SEM observations (Figures 2 and 3). Consequently, in the C:G hybrid nanofillers, the CNC may play the role of cross-linking agents, helping the PVA chains to keep its mechanical ductility. This is possible because the elongation at break of PVA-CNC was measured at $55.17 \%$, which is comparable to that measured for neat PVA $(64.98 \%)$ and its nanocomposites containing C:G hybrid nanofillers (58,9-64.29\%), while the elongation at break for PVA-GON was measured at $14.17 \%$. It is suggested that films suitable for food packaging should preferably strong and flexible. This trend is observed in PVA nanocomposite films reinforced with $\mathrm{C}: \mathrm{G}$ hybrids fabricated in the present work.

From Figure 7, the studied tensile properties were affected by the variation of mass ratio of $\mathrm{CNC}$ and GON in the C:G hybrid nanofillers. Notably, the reinforcing efficiency of C:G$1: 2$ is higher than that of $\mathrm{C}: \mathrm{G}-1: 1$ and $\mathrm{C}: \mathrm{G}-2: 1$, because the PVA-C:G-1:2 nanocomposite shows the superior improvement of the tensile properties, while the relatively inferior improvement is observed for the PVA-C:G-2:1 nanocomposite, thus confirming that the synergetic effect was more pronounced in the hybrid nanofiller containing a high amount of GON (C:G-1:2). This can be attributed to the flat surface of the GON which led to an enhanced mechanical interlocking with the polymer chains and an enlarged interphase zone at nanofiller-polymer interface (El Achaby \& Qaiss, 2013). This effect was less pronounced in the $\mathrm{C}: \mathrm{G}$ hybrid nanofiller containing a low amount of GON (C:G-2:1) because the presence of a high amount of CNC can completely cover the surface of GON, and the interphase zone at nanofiller-polymer interface can be reduced. This is possible because the $\mathrm{C}: \mathrm{G}$ hybrid nanofiller containing equal amounts of $\mathrm{CNC}$ and GON shows an intermediate reinforcing efficiency. 


\subsection{Moisture uptake of PVA nanocomposite films}

Moisture uptake rate (MUR) was analyzed in order to evaluate the effect of C:G hybrid nanofillers on PVA films at a constant relative humidity (RH). The MUR is a highly important property to consider in certain industries like food packaging. In this application, films should prevent or at least reduce MUR for food preservation. In general, a reduced MUR is required for moisture-sensitive food products (Bilbao-Sainz, Avena-Bustillos, Wood, Williams, \& McHugh, 2010; George \& Siddaramaiah, 2012). Figure 8 plots the MUR for all studied films as a function of storage time (3-6 hours) upon conditioning at $75 \%$ RH. For all films, it is apparent that the MUR remained constant after a storage time of 5 hours of conditioning, which is known as the equilibrium moisture content (EMC) at a particular RH (George et al., 2014). The neat PVA film had a much greater EMC than its nanocomposites with different nanofillers. The EMC of the neat PVA was observed at $28.93 \%$, which can be attributed to the hydrophilic nature of the PVA polymer (George et al., 2012). Unlike the neat PVA, the PVA-CNC and PVA-GON nanocomposites exhibited an EMC of $21.84 \%$ and $20.30 \%$, respectively, which is lower than that observed for the neat PVA and higher than that observed for the PVA-C:G nanocomposites. From Figure 8, the nanocomposites of PVAC:G-2:1, PVA-C:G-1:1 and PVA-C:G-1:2 showed an EMC of 15.36, 15.63 and $10.19 \%$, respectively. Therefore, it can be concluded that the moisture resistance of the PVA polymer largely improved with the addition of C:G hybrid nanofillers, especially for C:G-1:2 hybrid nanofiller. This improvement can be attributed to the presence of strong hydrogen bonding interactions between the PVA matrix and C:G hybrid nanofillers, which minimizes the interaction of water with the nanocomposites (George et al., 2012, 2014). This trend was also reported by George et al. (2014) who demonstrated that the hydrogen bonding interactions could reduce the number of sorption sites available for moisture absorption in the hydrophilic polymer based nanocomposites, reducing the EMC at a high RH. Herein, the well-dispersed 
C:G hybrid nanofiller acted as an interpenetrated network within the PVA matrix and prevented moisture absorption in the nanocomposite films when exposed to a particular $\mathrm{RH}$. The prevention of moisture absorption is very beneficial applications like food packaging, especially for moisture-sensitive food products.

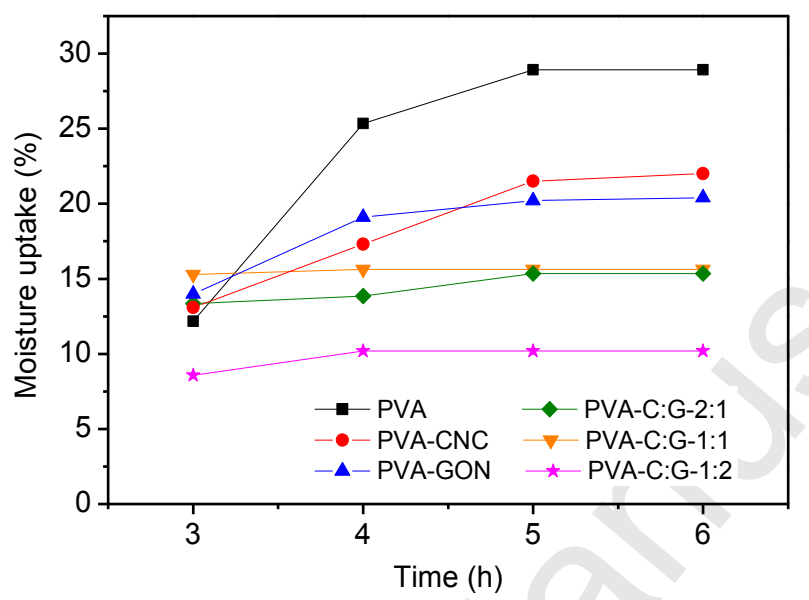

Figure 8: Moisture uptake of PVA and its nanocomposite films with CNC, GON and C:G (C:G-2:1, C:G-1:1 and C:G-1:2) hybrid nanofillers.

\section{Conclusions}

The reinforcing efficiency of graphene oxide nanosheets (GON) in polymer nanocomposites has been largely limited, because this water-dispersible nanofiller, at high loading level, tends to agglomerate within the polymer matrix. In this work we demonstrated that the combination of cellulose nanocrystals (CNC) and GON in a novel hybrid nanofiller (C:G hybrid) was highly effective to overcome the agglomeration phenomenon. After their combination, the $\mathrm{CNC}$ were found to be adsorbed on the surface of GON, forming a new network structure via hydrogen bonding interactions between the functional groups present in the surface of each nanomaterial. Three C:G hybrid nanofillers were prepared by varying the weight ratio of CNC and GON (2:1, 1:1 and 1:2) and their incorporation into PVA matrix was successfully achieved via solvent casting method leading to PVA-C:G-2:1, PVA-C:G-1:1 and PVA-C:G1:2 nanocomposite films. Due to the strong interfacial interaction and the synergistic effect 
generated from the combination of the two kinds of nanofillers ( $\mathrm{CNC}$ and $\mathrm{GON})$, the Young's modulus, tensile strength and toughness of all the resulting PVA-C:G nanocomposites were largely enhanced, and the elongation at break basically remained compared to pure PVA. Simultaneously, the glass and melting temperatures as well as the moisture sorption of the resulting nanocomposites were also improved. It was found also that the C:G hybrid nanofiller containing a high amount of GON (C:G-1:2) showed a superior reinforcing efficiency in the PVA nanocomposites. Comparatively, the results obtained for the C:G hybrid nanofiller reinforced nanocomposite films were largely superior compared to those found for nanocomposites containing either CNC or GON nanofillers, at the same loading level. This finding was attributed to the synergistic effect of 1-D elongated CNC and 2-D exfoliated GON, which improves the dispersion homogeneity by avoiding the agglomeration phenomenon within the polymer, resulting in nan ocomposites with enhanced properties compared to those prepared from single nanofiller ( $\mathrm{CNC}$ or $\mathrm{GON})$. The preparation of this novel hybrid nanofiller and its incorporation into the polymer matrix provided a novel method to develop innovative materials, mainly by improving the mechanical properties of nanocomposite films in applications where good strength, ductility and reduced moisture absorption are required. Food packaging is one example of such applications.

\section{Acknowledgements}

The financial assistance of the Office Chérifien des Phosphates (OCP Group) in the Moroccan Kingdom toward this research is hereby acknowledged. This work was supported also by grant from the OCP Foundation. We equally thank all administrative and technical support teams of the UM6P. 


\section{References}

573

574

575

576

577

578

579

580

581

582

583

584

585

586

587

588

589

590

591

592

593

594

595

Bilbao-Sainz, C., Avena-Bustillos, R. J., Wood, D. F., Williams, T. G. \& McHugh, T. H. (2010). Composite edible films based on hydroxypropyl methylcellulose reinforced with microcrystalline cellulose nanoparticles. Journal of Agriculture and Food Chemistry, 58, 3753-3760.

Chatterjee, S., Nafezarefi, F., Tai, N. H., Schlagenhauf, L., Nuesch, F. A., \& Chu, B. T. T. (2012). Size and synergy effects of nanofiller hybrids including graphene nanoplatelets and carbon nanotubes in mechanical properties of epoxy composites. Carbon, 50, 5380-5386.

Chen, Q., Liu, P., Sheng, C., Zhou, L., Duan, Y., \& Zhang, J. (2014). Tunable self-assembly structure of graphene oxide/cellulose nanocrystal hybrid films fabricated by vacuum filtration technique. RSC Advances, 4, 39301-39304.

Chivrac, F., Pollet, E., \& Avérous, L. (2009). Progress in nanobiocomposites based on polysaccharides and nanoclays. Materials Science and Engineering: R: Reports, 67, $1-17$.

Dhibar, S., Bhattacharya, P., Ghosh, D., Hatui, G., \& Das, C. K. (2014). Graphene-singlewalled carbon nanotubes-poly (3-methylthiophene) ternary nanocomposite for supercapacitor electrode materials. Industrial and Engineering Chemistry Research, $53,13030-13045$.

El Achaby, M., Arrakhiz, F. E., Vaudreuil, S., Essassi, E., \& Qaiss, A. (2012a). Piezoelectric $\beta$-polymorph formation and properties enhancement in graphene oxide - PVDF nanocomposite films. Applied Surface Science, 258, 7668-7677.

El Achaby, M., Arrakhiz, F. E., Vaudreuil, S., Qaiss, A., Bousmina, M., \& Fassi-Fehri, O. (2012b). Mechanical, thermal, and rheological properties of graphene-based 
polypropylene nanocomposites prepared by melt mixing. Polymer Composites, 33, 733-744.

El Achaby, M., Arrakhiz, F. E., Vaudreuil, S., Essassi, E., Qaiss, A., \& Bousmina, M. (2013a). Preparation and characterization of melt-blended graphene nanosheetspoly (vinylidene fluoride) nanocomposites with enhanced properties. Journal of Applied Polymer Science, 127, 4697-4707.

El Achaby, M., \& Qaiss, A. (2013b). Processing and properties of polyethylene reinforced by graphene nanosheets and carbon nanotubes. Materials and Design, 44, 81-89.

El Achaby, M., Essamlali, Y., El Miri, N., Snik, A., Abdelouahdi, K., Fihri, A., Zahouily M., \& Solhy, A. (2014). Graphene oxide reinforced chitosan/polyvinylpyrrolidone polymer bio-nanocomposites. Journal of Applied Polymer Science, 131, doi: 10.1002/app.41042.

El Miri, N., Abdelouahdi, K., Zahouily, M., Fihri, A., Barakat, A., Solhy, A., \& El Achaby, M. (2015a). Bio-nanocomposite films based on cellulose nanocrystals filled polyvinyl alcohol/chitosan polymer blend. Journal of Applied Polymer Science, 132, doi:10.1002/app.42004.

El Miri, N., Abdelouahdi, K., Barakat, A.,Zahouily, M., Fihri, A.,Solhy, A., \& El Achaby, M. (2015b). Bio-nanocomposite films reinforced with cellulose nanocrystals: rheology of film-forming solutions, transparency, water vapor barrier and tensile properties of films. Carbohydrate Polymers, 129, 156-167.

Fan, J., Shi, Z., Zhang, L., Wang, J., \& Yin, J. (2012). Aramid nanofiber-functionalized graphene nanosheets for polymer reinforcement. Nanoscale, 4, 7046-7055.

Fortunati, E., Luzi, F., Puglia, D., Terenzi, A., Vercellino, M., Visai, L., Santulli, C., Torre, L., \& Kenny, J. M. (2013a). Ternary PVA nanocomposites containing cellulose 

nanocrystals from different sources and silver particles: Part II. Carbohydrate Polymers, 97, 837-848.

Fortunati, E., Puglia, D., Luzi, F., Santulli, C., Kenny, J. M., \& Torre, L. (2013b). Binary PVA bio-nanocomposites containing cellulose nanocrystals extracted from different natural sources: Part I. Carbohydrate Polymers, 97, 825-836.

George, J., Sajeevkumar, V. A., Ramana, K. V., Sabapathy, S. N., \& Siddaramaiah. (2012). Augmented properties of PVA hybrid nanocomposites containing cellulose nanocrystals and silver nanoparticles. Journal of Materials Chemistry, 22, 2243322439.

George, J., \& Siddaramaiah. (2012). High performance edible nanocomposite films containing bacterial cellulose nanocrystals. Carbohydrate Polymers, 87, 20312037.

George, J., Kumar, R., Sajeevkumar, V. A., Ramana, K. V., Rajamanickam, R., Abhishek, V., Nadanasabapathy, S., \& Siddaramaiah. (2014). Hybrid HPMC nananocomposites containing bacterial cellulose nanocrystals and silver nanoparticles. Carbohydrate Polymers, 105, 285-292.

Hu, K., Kulkarni, D. D., Choi, I., \& Tsukruk, V. V. (2014). Graphene-polymer nanocomposites for structural and functional applications. Progress in Polymer Science, 39, 1934-1972.

Huang, H. D., Ren, P. G., Chen, J., Zhang, W. Q., Ji, X., \& Li, Z. M. (2012). High barrier graphene oxide nanosheet/poly(vinyl alcohol) nanocomposite films. Journal of Membrane Science, 409-410, 156-163.

Huang, S., Peng, H., Tjiu, W. W., Yang, Z., Zhu, H., Tang, T., Liu, T. (2010). Assembling Exfoliated Layered Double Hydroxide (LDH) Nanosheet/Carbon Nanotube (CNT) 
Hybrids via Electrostatic Force and Fabricating Nylon Nanocomposites. The Journal of Physical Chemistry B, 114, 16766-16772.

646

647

648

649

650

651

652

653

654

655

656

657

658

659

660

661

662

663

664

665

666

Hummers, W.S., \& Offeman, R. E. (1958). Preparation of Graphitic Oxide. Journal of American Chemical Society, 80, 1339-1339.

Jose, J., Al-Harthi, M. A., AlMaadeed, M. A., Dakua, J. B., \& De, S. K. (2015). Effect of graphene loading on thermomechanical properties of poly(vinyl alcohol)/starch blend. Journal of Applied Polymer Science, 132, doi:10.1002/app.41827.

Jose, J. P., \& Thomas, S. (2014a). Alumina-clay nanoscale hybrid filler assembling in crosslinked polyethylene based nanocomposites: mechanics and thermal properties. Physical Chemistry Chemical Physics, 16, 14730-14740.

Jose, J. P., \& Thomas, S. (2014b). XLPE based $\mathrm{Al}_{2} \mathrm{O}_{3}$-clay binary and ternary hybrid nanocomposites: self-assembly of nanoscale hybrid fillers, polymer chain confinement and transport characteristics. Physical Chemistry Chemical Physics, 16, 20190-20201.

Layek, R. K., Kundu, A., \& Nandi, A. K. (2013). High-performance nanocomposites of sodium carboxymethylcellulose and graphene oxide. Macromolecular Materials and Engineering, 298, 1166-1175.

Li, D., Muller, M. B., Gilje, S., Kaner, R. B., \& Wallace, G. G. (2008). Processable aqueous dispersions of graphene nanosheets. Nature Nanotechnology, 3, 101-105.

Li, X., Ma, L., Zhang, H., Wang, S., Jiang, Z., Guo, R., Wu, H., Cao, X., Yang, J., \& Wang, B. (2015). Synergistic effect of combining carbon nanotubes and graphene oxide in mixed matrix membranes for efficient $\mathrm{CO}_{2}$ separation. Journal of Membrane Science, $479,1-10$. 
667

668

669

670

671

672

673

674

675

676

677

678

679

680

681

682

683

684

685

686

687

688

689

690

691

Li, Y., Yang, T., Yu, T., Zheng, L., \& Liao, K. (2011). Synergistic effect of hybrid carbon nanotube-graphene oxide as a nanofiller in enhancing the mechanical properties of PVA composites. Journal of Materials Chemistry, 21, 10844-10851.

Naffakh, M., Diez-Pascual, A. M., Marco, C., \& Ellis, G. (2012). Morphology and thermal properties of novel poly (phenylene sulfide) hybrid nanocomposites based on single-walled carbon nanotubes and inorganic fullerene-like $\mathrm{WS}_{2}$ nanoparticles. Journal of Materials Chemistry, 22, 1418-1425.

Njuguna, J., Silva, F., \& Sachse, S. (2011). Nanofibers - production, properties and functional applications. In T. Lin (Eds.), Nanocomposites for vehicle structural applications (pp. 401-434). ISBN: 978-953-307-420-7. In Tech, doi: 10.5772/23261.

Paul, D. R., \& Robeson, L. M. (2008). Polymer nanotechnology: Nanocomposites. Polymer, 49, 3178-3204.

Peresin, M. S., Habibi, Y., Zoppe, J. O., Pawlak, J. J., \& Rojas, O. J. (2010). Nanofiber composites of polyvinyl alcohol and cellulose nanocrystals: manufacture and characterization. Biomacromolecules, 11, 674-681.

Pradhan, B., Roy, S., Srivastava, S. K., \& Saxena, A. (2015). Synergistic effect of carbon nanotubes and clay platelets in reinforcing properties of silicone rubber nanocomposites. Journal of Applied Polymer Science, doi: 10.1002/app.41818.

Rodríguez-González, C., Martínez-Hernández, A. L., Castaño, V. M., Kharissova, O. V., Ruoff, R. S., \& Velasco-Santos, C. (2012). Polysaccharide nanocomposites reinforced with graphene oxide and keratin-grafted graphene oxide. Industrial and Engineering Chemistry Research, 51, 3619-3629.

Sadasivuni, K. K., Kafy, A., Zhai, L., Ko, H. U., Mun, S., \& Kim, J. (2015). Transparent and flexible cellulose nanocrystal/reduced graphene oxide film for proximity sensing. Small, 11, 994-1002. 
692

693

694

695

696

697

698

699

700

701

702

703

704

705

706

707

708

709

710

711

712

713

714

715

Shen, X. J., Pei, X. Q., Liu, Y., \& Fu, S. Y. (2014). Tribological performance of carbon nanotube-graphene oxide hybrid/epoxy composites. Composites Part B: Engineering, 57,120-125.

Soykeabkaew, N., Laosat, N., Ngaokla, A., Yodsuwan, N., \& Tunkasiri, T. (2012).

Reinforcing potential of micro and nano-sized fibers in the starch-based biocomposites. Composites Science and Technology, 72, 845-852.

Szabo, T., Berkesi, O., Forgo, P., Josepovits, K., Sanakis, Y., Petridis, D., \& Dekany, I. (2006). Evolution of surface functional groups in a series of progressively oxidized graphite oxides. Chemistry of Materials, 18, 2740-2749.

Tang, C., Chen, N., Zhang, Q., Wang, K., Fu, Q., \& Zhang, X. (2009). Preparation and properties of chitosan nanocomposites with nanofillers of different dimensions. Polymer Degradation and Stability, 94, 124-131.

Tang, C., Hackenberg, K., Fu, Q., Ajayan, P. M., \& Ardebili, H. (2012). High ion conducting polymer nanocomposite electrolytes using hybrid nanofillers. Nano Letters, 12 , $1152-1156$.

Teixeira, E. d. M., Bondancia, T. J., Teodoro, K. B. R., Corrêa, A. C., Marconcini, J. M., \& Mattoso, L. H. C. (2011). Sugarcane bagasse whiskers: extraction and characterizations. Industrial Crops and Products, 33, 63-66.

Valentini, L., Cardinali, M., Fortunati, E., Torre, L., \& Kenny, J. M. (2013). A novel method to prepare conductive nanocrystalline cellulose/graphene oxide composite films. Materials Letters, 105, 4-7.

Wang, Q., Li, G., Zhang, J., Huang, F., Lu, K., \& Wei, Q. (2014b). PAN nanofibers reinforced with MMT/GO hybrid nanofillers. Journal of Nanomaterials, 2014, 298021. 
Wang, Y., Tian, H., \& Zhang, L. (2010). Role of starch nanocrystals and cellulose whiskers in synergistic reinforcement of waterborne polyurethane. Carbohydrate Polymers, 80 , $665-671$.

Wang, Y., Yu, J., Dai, W., Wang, D., Song, Y., Bai, H., Zhou, X., Li, C., Lin, C.T., \& Jiang, N. (2014a). Epoxy composites filled with one-dimensional SiC nanowires-twodimensional graphene nanoplatelets hybrid nanofillers. RSC Advances, 4, 5940959417.

Xu, X., Yang, Y. Q., Xing, Y. Y., Yang, J. F., \& Wang, S. F. (2013). Properties of novel polyvinyl alcohol/cellulose nanocrystals/silver nanoparticles blend membranes. Carbohydrate Polymers, 98, 1573-1577.

Xu, Y., Hong, W., Bai, H., Li, C., \& Shi, G. (2009). Strong and ductile poly(vinyl alcohol)/graphene oxide composite films with a layered structure. Carbon, 47, $3538-3543$.

Yi, D. H., Yoo, H. J., Mahapatra, S. S., Kim, Y. A., \& Cho, J. W. (2014). The synergistic effect of the combined thin multi-walled carbon nanotubes and reduced graphene oxides on photothermally actuated shape memory polyurethane composites. Journal of Colloid and Interface Science, 432, 128-134.

Yu, H., Sun, B., Zhang, D., Chen, G., Yang, X., \& Yao, J. (2014). Reinforcement of biodegradable poly(3-hydroxybutyrate-co-3-hydroxyvalerate) with cellulose nanocrystal/silver nanohybrids as bifunctional nanofillers. Journal of Materials Chemistry B, 2, 8479-8489.

Yuan, B., Bao, C., Qian, X., Jiang, S., Wen, P., Xing, W., Song, L., Liew, K. M., \& Hu, Y. (2014). Synergetic dispersion effect of graphene nanohybrid on the thermal stability and mechanical properties of ethylene vinyl acetate copolymer nanocomposite. Industrial and Engineering Chemistry Research, 53, 1143-1149. 
Zhang, C., Huang, S., Tjiu, W. W., Fan, W., \& Liu, T. (2012). Facile preparation of waterdispersible graphene sheets stabilized by acid-treated multi-walled carbon nanotubes and their poly(vinyl alcohol) composites. Journal of Materials Chemistry, 22, 2427-2434.

Zhang, J., Wang, J., Lin, T., Wang, C. H., Ghorbani, K., Fang, J., \& Wang, X. (2014). Magnetic and mechanical properties of polyvinyl alcohol (PVA) nanocomposites with hybrid nanofillers-graphene oxide tethered with magnetic $\mathrm{Fe}_{3} \mathrm{O}_{4}$ nanoparticles. Chemical Engineering Journal, 237, 462-468.

Zhang, J., Zhang, C., \& Madbouly, S. A. (2015). In situ polymerization of bio-based thermosetting polyurethane/graphene oxide nanocomposites. Journal of Applied Polymer Science, 132, doi:10.1002/app.41751.

Zhang, S., Yin, S., Rong, C., Huo, P., Jiang, Z., \& Wang, G. (2013). Synergistic effects of functionalized graphene and functionalized multi-walled carbon nanotubes on the electrical and mechanical properties of poly(ether sulfone) composites. European Polymer Journal, 49, 3125-3134.

Zhao, M. Q., Zhang, Q., Huang, J. Q., \& Wei, F. (2012). Hierarchical nanocomposites derived from nanocarbons and layered double hydroxides - properties, synthesis, and applications. Advanced Functional Materials, 22, 675-694.

\section{Highlights}

- Cellulose nanocrystals (CNC) and graphene oxide (GON) were combined to get a novel hybrid nanofiller

- 3D network microstructure was formed by the combination of CNC and GON two kinds of nanomaterials

- Hybrid nanofiller was used to enhance the tensile properties of PVA nanocomposites - Large increase of tensile properties of PVA was observed due to the synergistic effect 


\section{8}

36

Comment citer ce document :

El Miri, N.. El Achaby, M., Fihri, A., Larzek, M., Zahouily, M., Abdelouahdi, K., Barakat, A.. Solhy, A. (2016). Synergistic effect of cellulose nanocrystals/graphene oxide nanosheets as

Page 36 of 36 functional hybrid nanofiller for enhancing properties of PVA nanocomposites. Carbohydrate 